\title{
A Qualitative Study of the Influence of Grooved Mold Surface Topography on the Formation of Surface Marks on As-Cast Ingots of Aluminum Alloy 3003
}

\author{
Prince N. Anyalebechi \\ School of Engineering, Grand Valley State University, Allendale, USA \\ Email: anyalebp@gvsu.edu
}

How to cite this paper: Anyalebechi, P.N. (2020) A Qualitative Study of the Influence of Grooved Mold Surface Topography on the Formation of Surface Marks on As-Cast Ingots of Aluminum Alloy 3003. Materials Sciences and Applications, 11, 263-284. https://doi.org/10.4236/msa.2020.114018

Received: February 29, 2020

Accepted: April 27, 2020

Published: April 30, 2020

Copyright () 2020 by author(s) and Scientific Research Publishing Inc. This work is licensed under the Creative Commons Attribution International License (CC BY 4.0).

http://creativecommons.org/licenses/by/4.0/

(c) (i) Open Access

\begin{abstract}
The effects of the wavelength and orientation of machined grooves on a mold surface, casting speed, and melt superheat on the formation of surface marks on as-cast ingots were studied with an immersion casting tester and copper mold chill blocks. The mold surface topographies included a polished smooth surface, and those with machined unidirectional parallel contoured grooves oriented either parallel (vertical) or perpendicular (horizontal) to the casting direction. The unidirectional grooves were $0.232 \mathrm{~mm}$ deep with wavelength or spacing between 1 and $15 \mathrm{~mm}$. The casting speed and melt superheat were between 1 and $200 \mathrm{~mm} / \mathrm{s}$, and 10 and $50 \mathrm{~K}$, respectively. Two primary types of surface marks were observed on ingots cast with the copper mold with smooth surface topography, namely the finer and closely spaced ripples (Type I), and the widely spaced but coarser laps (Type II). The latter were more prevalent at the higher casting speeds and melt superheats. Qualitatively, formation of both types of surface marks on the as-cast ingots of the aluminum alloy 3003 appeared to be alleviated by increase in casting speed and melt superheat, and by the use of molds with grooved surface topography. In fact, casting with a mold surface with $1 \mathrm{~mm}$ spaced grooves that are perpendicular to the casting direction eliminated the formation of surface marks at casting speeds greater than $1 \mathrm{~mm} / \mathrm{s}$. It also improved the uniformity of the ingot subsurface microstructure and eliminated the associated subsurface segregation.
\end{abstract}

\section{Keywords}

Ripples, Laps, Grooved Mold Surface Topography, Casting, Aluminum Alloy, Lap Formation 


\section{Introduction}

Defective surface marks such as ripples and laps form on as-cast surfaces of aluminum and aluminum alloy ingots and on their continuously cast slabs and bars [1]-[11]. These defects and their associated non-uniform subsurface microstructure make it difficult to produce surface-sensitive products such as aluminum foil, beverage can sheets, and aircraft and automotive body sheet from the cast ingots without the expensive scalping operation [12]. This is despite improvement in ingot casting technology such as the development of electromagnetic casting and low head composite mold casting processes. Scalping of semi-continuously cast ingots and billets, and continuously cast bar surfaces is a generally accepted practice in the aluminum industry [12]. It involves the removal of 12.0 to $25 \mathrm{~mm}$ of the as-cast surface and subsurface of the cast ingots and billets before subsequent fabrication of the ingots into different aluminum products by forging, extrusion, and rolling. While scalping as much as $25 \mathrm{~mm}$ of the surface of a large ingot may represent a very small loss relative to the total volume of cast metal, removing the same depth of material from a small bar or thin slab constitutes a prohibitively large fraction of scrap. Besides, scalping is an extra process step that requires capital equipment. In fact, this extra process step costs the aluminum industry more than ten million dollars a year and reduces recovery.

Results of various experimental studies suggest that the formation of surface defects on cast aluminum alloy products can be directly attributed to the non-uniform rate of heat transfer at the mold-casting interface [13]-[20]. Similar studies have been conducted on other types of metals and their alloys [21]-[26]. They suggest that under certain casting conditions, non-uniform heat transfer at the early stages of the molten metal making contact with the mold surface causes both lap and/or ripple formation on the as-cast surface. The rate and uniformity of heat transfer in casting operations can be controlled by the manipulation of different casting process variables such as molten metal temperature, nature and method of mold cooling and/or insulation, mold material, and mold surface topography. The use of machined grooved mold surface topography in casting operations has been substantially investigated [27]-[42]. The surface topographies that have been examined have varied from unidirectional grooves to discrete recessions or cavities. The studies have yielded conflicting results and only three of the studies [29] [30] [39] have been conducted on aluminum and its alloys. In the three studies, the effects of process variables and mold surface topographical parameters such as the wavelength (or pitch), depth, and orientation of the surface topography were not investigated. In this study, the effects of the wavelength and orientation of parallel contoured unidirectional grooves on a mold surface on the formation of surface marks on as-cast ingots and attendant subsurface microstructure are carefully investigated.

\section{Experimental Procedure}

This study was conducted with a computer-controlled immersion casting tester 
[43] [44] [45] [46] and rectangular solid pure copper mold chill blocks with different surface topographies, namely a smooth and different unidirectional grooved surface topographies. As described elsewhere [43] [44] [45] [46], the immersion tester consisted of: 1) a chill block (mold) with the desired surface topography, 2) a programmable servo motor with an electric cylinder actuator designed to move the chill block (mold) in a controlled and repeatable manner at speeds of up to $25 \mathrm{~mm} / \mathrm{s}, 3$ ) a system for measuring temperature as a function of time at a fast rate, 4) an electric resistance furnace, and 5) a $254 \mathrm{~mm}$ diameter graphite crucible coated with boron nitride for melting and holding the molten metal. The mass of the aluminum alloy melt was $23.4 \mathrm{~kg}$ and its depth in the crucible was $457.3 \mathrm{~mm}$.

The copper chill blocks were $33 \mathrm{~mm}$ thick $\times 120 \mathrm{~mm}$ long $\times 100 \mathrm{~mm}$ wide. The surface of the non-grooved chill block was polished whereas the contoured groves on the grooved chill blocks were obtained by wire electric discharge machining (EDM). The grooves were unidirectional and oriented parallel or perpendicular to the casting direction (Figure 1). The peak-to-valley depth of the grooves for each of the four mold surface topographies was $0.232 \mathrm{~mm}$, but the wavelengths (i.e., crest-to-crest separation or spacing) were 1, 5, 10, and $15 \mathrm{~mm}$. The arithmetic average roughness for the blocks with vertical or horizontal grooves with wavelength (spacing) of $1,5,10$, and $15 \mathrm{~mm}$ was $84,46,32$ and 15 $\mu \mathrm{m}$, respectively. However, the arithmetic average roughness $\left(R_{a}\right)$ of the surface of the non-grooved mold chill block was $0.12 \mu \mathrm{m}$. Thermocouples were located in the chill blocks at increasing distance $(1 \mathrm{~mm}, 18 \mathrm{~mm}$, and $33.5 \mathrm{~mm})$ from the polished or grooved surface in contact with the molten metal at 4, 20, 63 and 127 $\mathrm{mm}$ from the bottom.

The immersion shell casting testing involved the immersion of the solid copper chill blocks with the desired surface topography into a large bath of molten metal at a controlled rate and then reversing the mold to retrieve the planar solid

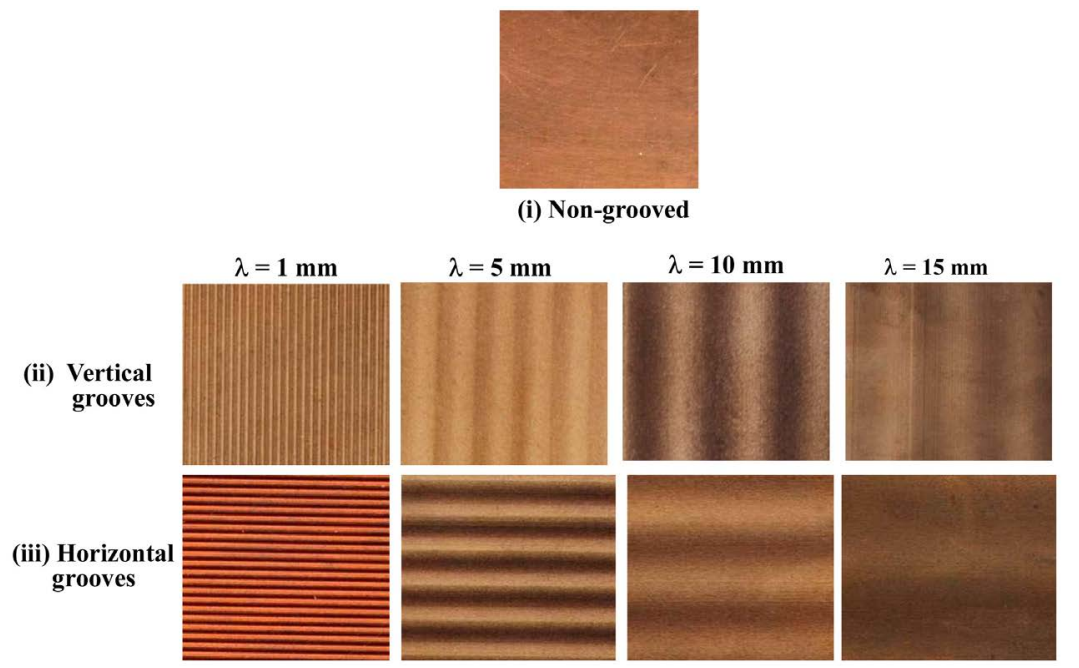

Figure 1. Photographs of the different grooved surface topographies of the copper mold chill blocks (wavelength, $\lambda$, is spacing between grooves). 
shell (Figure 2). Two thin wire hangers attached to the top edges of the mold facilitated the extraction of the solidified ingot shell during emersion of the mold. During emersion of the mold, most of the molten aluminum was drained from the surface of the solidified shell, so the shape of the solid shell was deemed to be a good representation of the morphology of the solidification growth front. To maintain a unidirectional solidification, every part of the copper mold block, except the machined surface, was covered with preheated $50 \mathrm{~mm}$ thick Marinite ${ }^{\circ}$ boards (Figure 2). This also ensured that for the duration of the immersion test, the thermal resistance at the melt-mold interface was dominant.

Majority of the immersion tests were conducted over a casting speed range of $1-100 \mathrm{~mm} / \mathrm{s}$ and at melt superheat 10, 25, and $50 \mathrm{~K}$. However, a few immersion tests were conducted at 0.5 and $200 \mathrm{~mm} / \mathrm{s}$. The range of casting speed investigated in the study is within the range of casting speed of commercial ingot, billet, and slab casting processes used in the aluminum industry [4]. At the end of immersion, the chill block was held in the melt for approximately $2 \mathrm{~s}$ to allow for sufficient shell growth, before it is removed (with the solidified shell) from the melt at $254 \mathrm{~mm} / \mathrm{s}$. The total mold-melt contact time was 4 to $100 \mathrm{~s}$, taking into consideration the immersion and emersion speeds, and $2 \mathrm{~s}$ hold time.

Prior to immersion tests, the chemical compositions of solid samples of the AA 3003 melt were determined by optical emission spectroscopy. On average the chemical composition of the AA 3003 melt consisted of $1.20 \mathrm{wt} \% \mathrm{Mn}, 0.57$ wt $\% \mathrm{Fe}, 0.24 \mathrm{wt} \% \mathrm{Si}, 0.024 \mathrm{wt} \% \mathrm{Ti}, 0.0006 \mathrm{wt} \% \mathrm{~B}$, and the remainder was aluminum. Titanium and boron were deliberately added to the melt for grain refining.

Characterization of the cast ingot shells involved the measurement of the distance between the surface marks and metallographic examination of the subsurface cast microstructure. The distance between the marks on the as-cast surface was measured manually with a metallurgical microscope-based image analyzer. Electron microprobe analysis was conducted on the subsurface microstructure to determine the extent of inverse segregation (or liquation) as a function of the

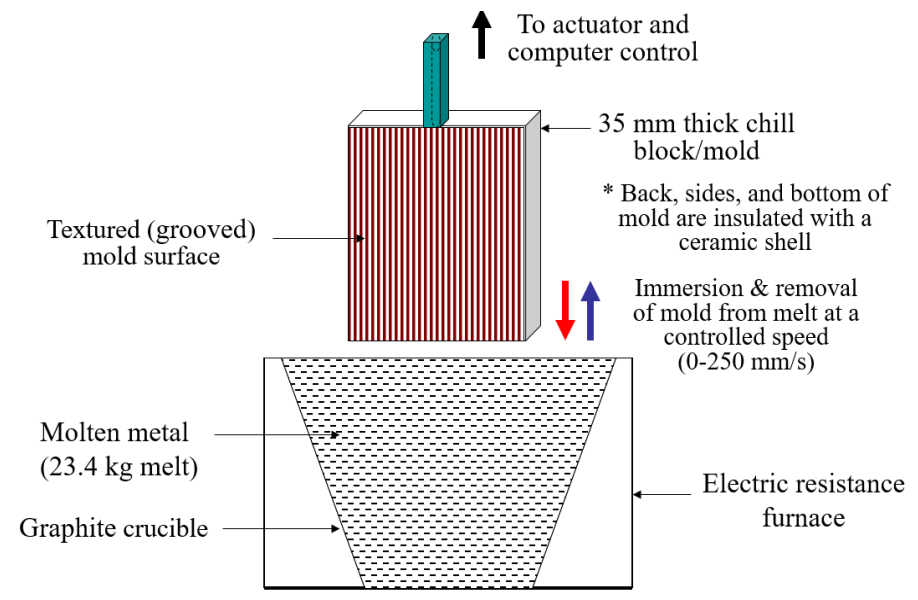

Figure 2. Schematic of the immersion ingot shell casting apparatus. 
mold surface topography. The method of inverse problem of heat conduction was used to determine the heat flux at the mold-melt interface based on the temperature data obtained with the thermocouples located in the molten metal and in the chill block.

\section{Results}

In this study, the quality of the as-cast chill surface of the shells was qualitatively evaluated on the basis of the presence and characteristics of geometric surface marks and defects such as ripples, wrinkles, and laps. These are periodic markings that form across the as-cast surface and perpendicular to the casting direction. They are known to form on the as-cast surfaces of ingots and continuous cast bars and slabs [1] [2] [3] [4]. Ripple marks are fine grooves with smaller wavelength or spacing. The wrinkles (also referred to as transverse depressions) are concave in nature and are coarser and more widely spaced than the ripples and laps. They are superimposed on the fine pattern of ripples. Lap marks are smaller than wrinkles but they are coarser, deeper, and more widely spaced than ripple marks [21] [22] [23]. Ripples, wrinkles, and laps are referred to as Types I, II, and III marks, respectively [21] [23]. In majority of cases, the ripple marks are prevalent through the laps and wrinkles. These terms are sometimes used interchangeably to describe surface marks on as-cast surfaces in the technical literature. Other terms used to describe these defects include folds, striations, bands, and cold shuts. In this study, only two main groups of the surface marks were observed-the finer closely spaced ripples (i.e., Type I), and the coarser and widely spaced wrinkles and laps (Types II and III), The latter will henceforth be referred to as lap marks or Type II surface marks. It is noteworthy that, the very small and finer ripples were also found between the coarser and more widely spaced lap marks.

The macrophotographs of the as-cast chill surface (i.e., mold-shell surface) of solid shell castings produced in the immersion tests with are given in Figure 3 and Figure 4. They clearly show that at all of the casting speeds and melt superheat investigated, immersion casting with the copper mold block with smooth surface topography produced shells with ripples and laps that are perpendicular to the casting direction. The lap marks decreased in frequency and appeared to be coarser and deeper with increase in casting speed (Figure 3) and melt superheat (Figure 4). In addition, the measured spacing between the laps appeared to increase with increase in casting speed, especially from 25 to $50 \mathrm{~mm} / \mathrm{s}$ (Figure 5). It also appeared to increase with increase in melt superheat especially at casting speeds above $10 \mathrm{~mm} / \mathrm{s}$ (Figure 6). In contrast, the spacing between the ripples (the finer surface marks) appeared to decrease with increase in casting speed and melt superheat. That is, the number of the ripples per unit distance increased.

The as-cast chill surfaces of the shells produced with copper mold chill blocks with grooves displayed the machined groove patterns on the mold chill blocks (Figures 7-12). This is particularly the case with the shells produced with mold 


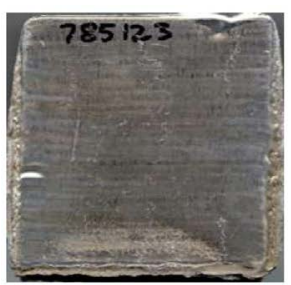

(a) $1 \mathrm{~mm} / \mathrm{s}$

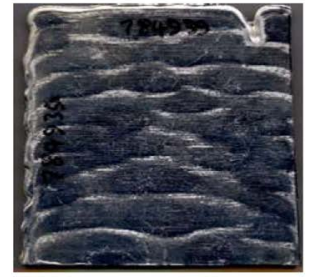

(d) $25 \mathrm{~mm} / \mathrm{s}$

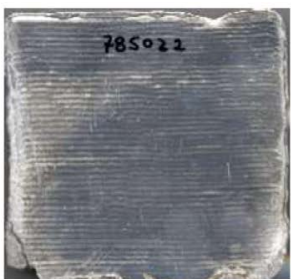

(b) $5 \mathrm{~mm} / \mathrm{s}$

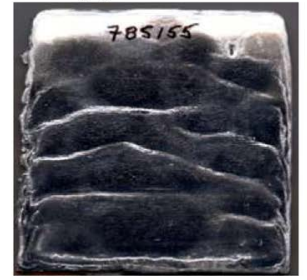

(e) $50 \mathrm{~mm} / \mathrm{s}$

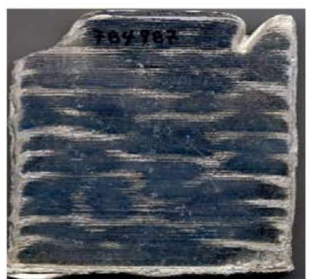

(c) $10 \mathrm{~mm} / \mathrm{s}$

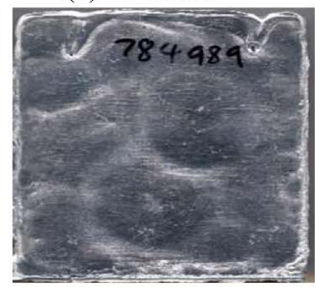

(f) $100 \mathrm{~mm} / \mathrm{s}$

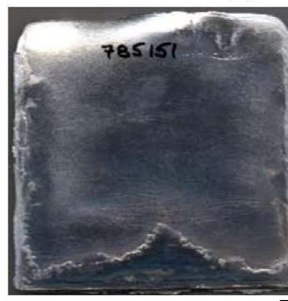

(g) $150 \mathrm{~mm} / \mathrm{s}$

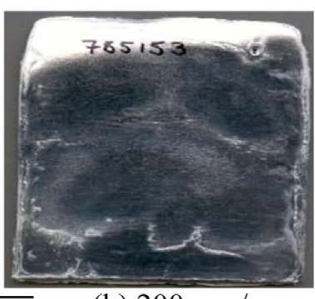

(h) $200 \mathrm{~mm} / \mathrm{s}$

Figure 3. Effect of casting speed on the as-cast surface of ingot shells produced by immersion of a copper block with machined smooth surface topography into an aluminum alloy 3003 melt at a superheat of $25 \mathrm{~K}$.

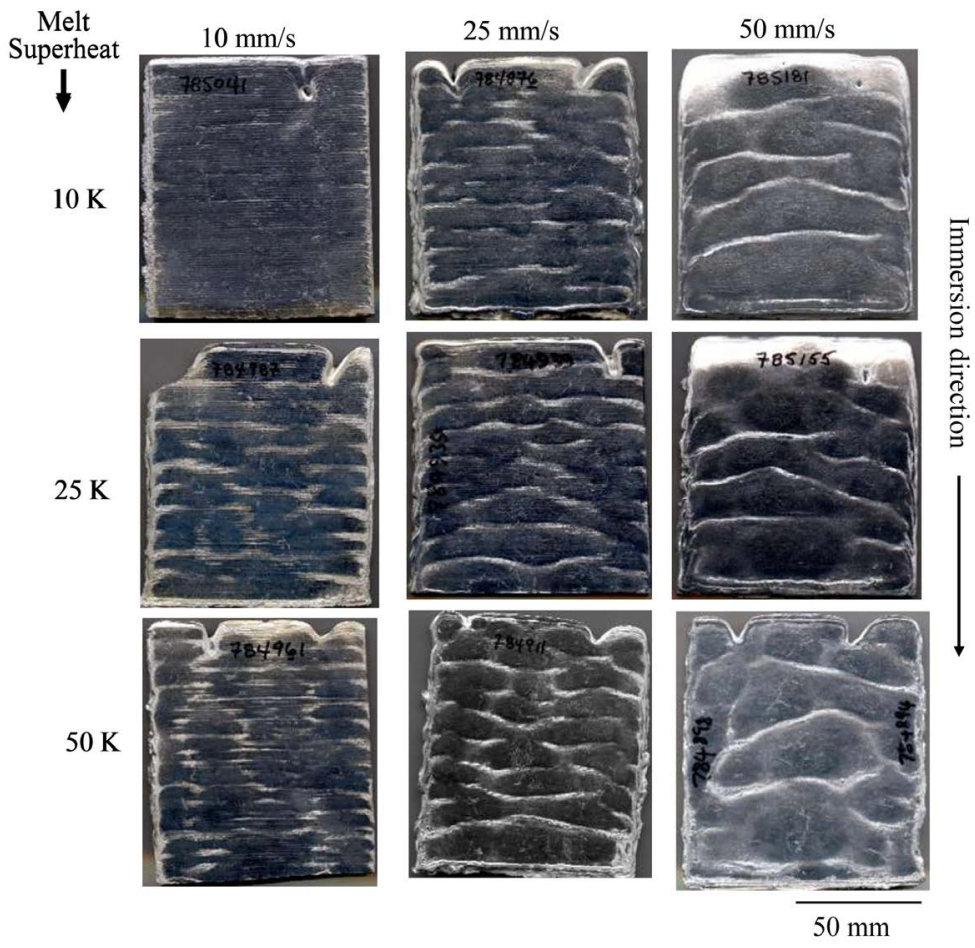

Figure 4. Effect of immersion (casting) speed and superheat on as-cast surface of ingot shells produced by immersion of a copper chill block with machined smooth surface topography into an aluminum alloy 3003 melt. 


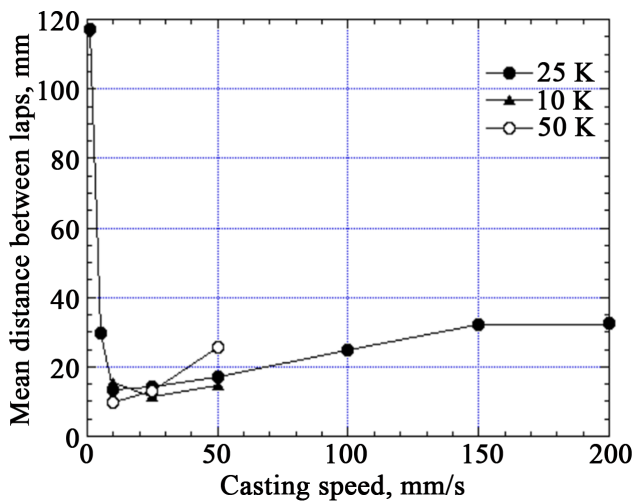

Figure 5. Effects of casting speed and melt superheat on the spacing between surface lap marks on the as-cast surface of AA 3003 ingot shells produced in casting immersion tests with a copper chill mold block with a machined smooth surface topography.

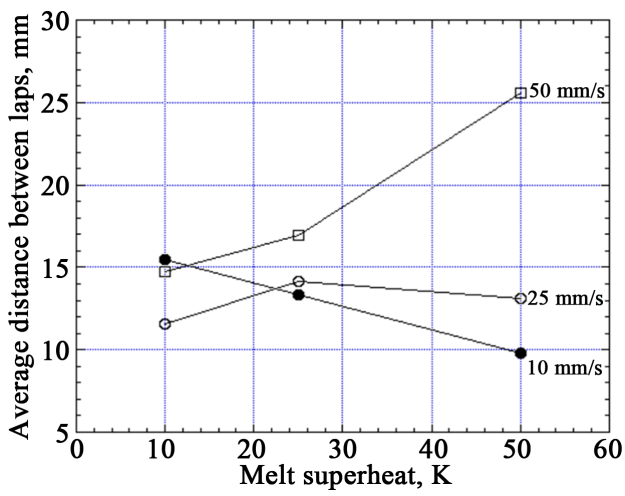

Figure 6. Effects of casting speed and melt superheat on the spacing between surface lap marks on the as-cast surface of aluminum alloy 3003 ingot shells produced in casting immersion tests with a copper chill mold block with a smooth surface topography.

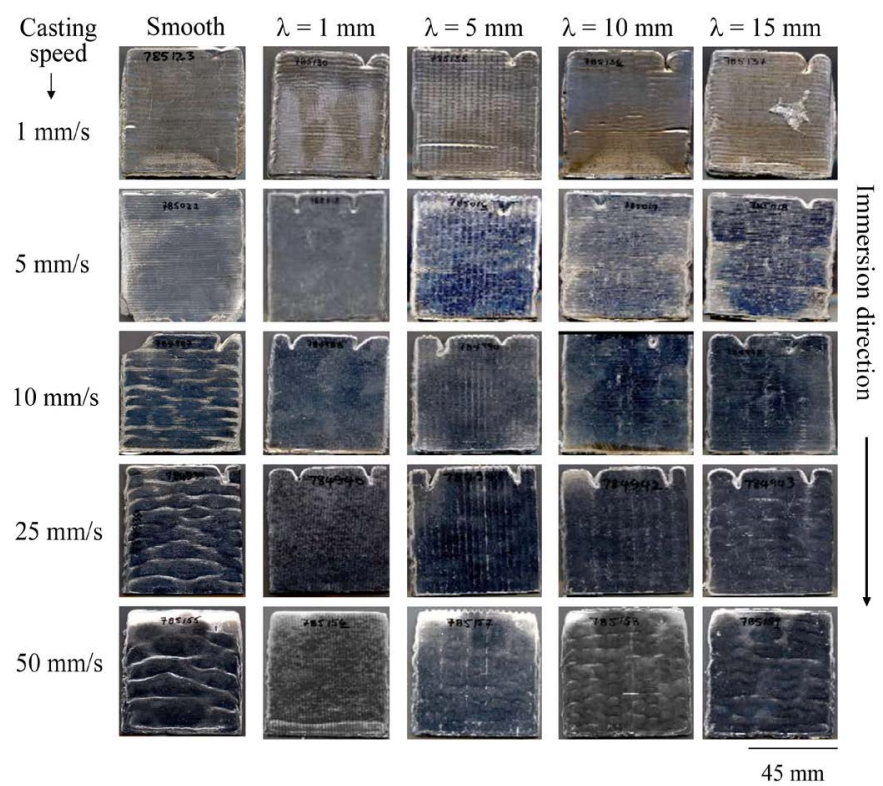

Figure 7. Effects of the wavelength of vertical grooves on a copper mold surface and casting speed on the as-cast surface quality of AA 3003 ingot shells at $25 \mathrm{~K}$ melt superheat. 


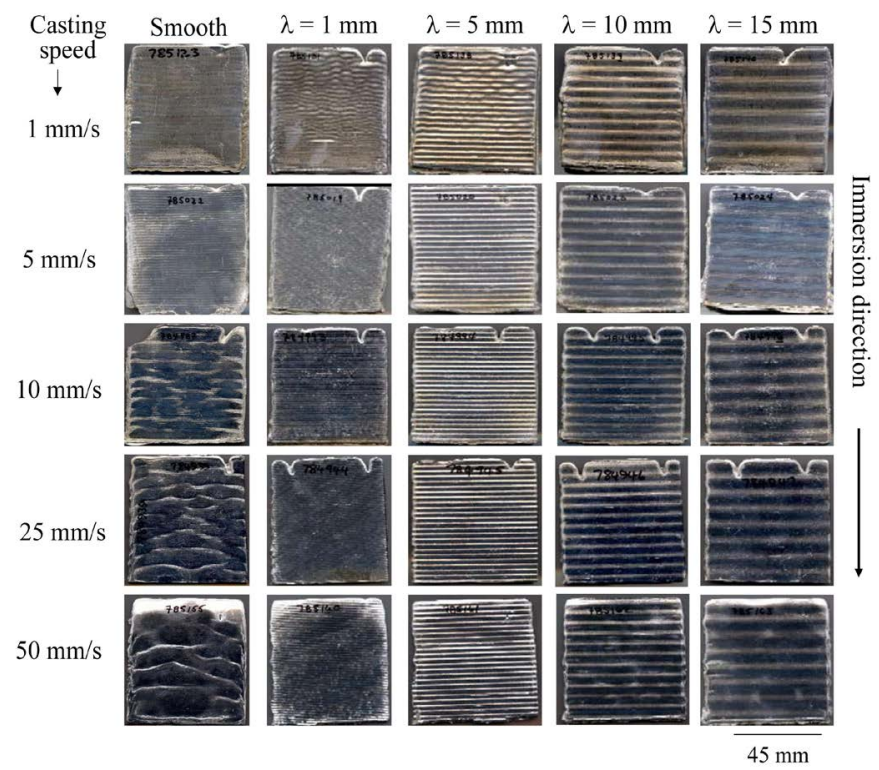

Figure 8. Effects of the wavelength of $0.232 \mathrm{~mm}$ deep horizontal grooves on a copper mold surface and casting speed on the as-cast surface quality of AA 3003 ingot shells at 25 K melt superheat.

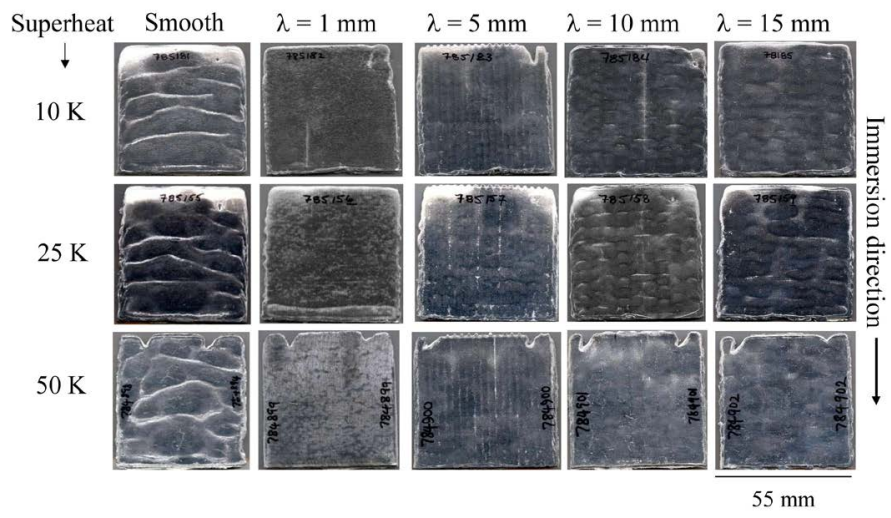

Figure 9. Effects of melt superheat and the wavelength of $0.232 \mathrm{~mm}$ deep vertical grooves on a copper mold surface on the as-cast surface quality of AA 3003 ingot shells cast at 50 $\mathrm{mm} / \mathrm{s}$.

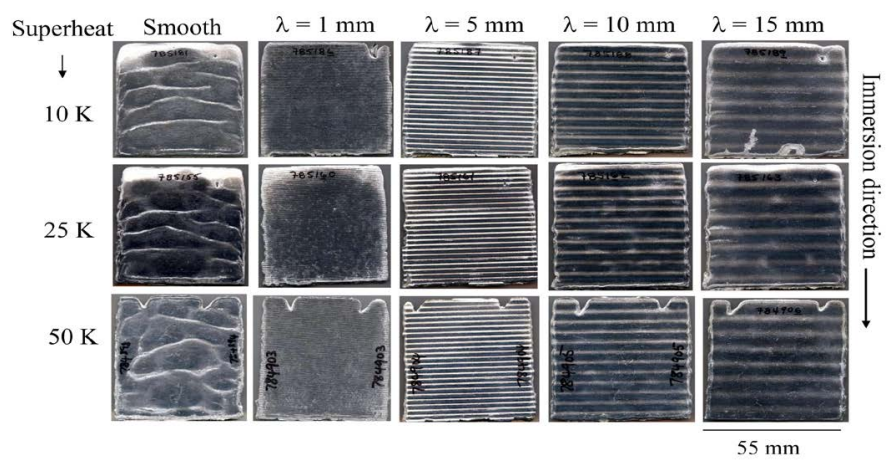

Figure 10. Effects of melt superheat and the wavelength of $0.232 \mathrm{~mm}$ deep grooves on a copper mold surface on the as-cast surface quality of AA 3003 ingot shells cast at 50 $\mathrm{mm} / \mathrm{s}$. 


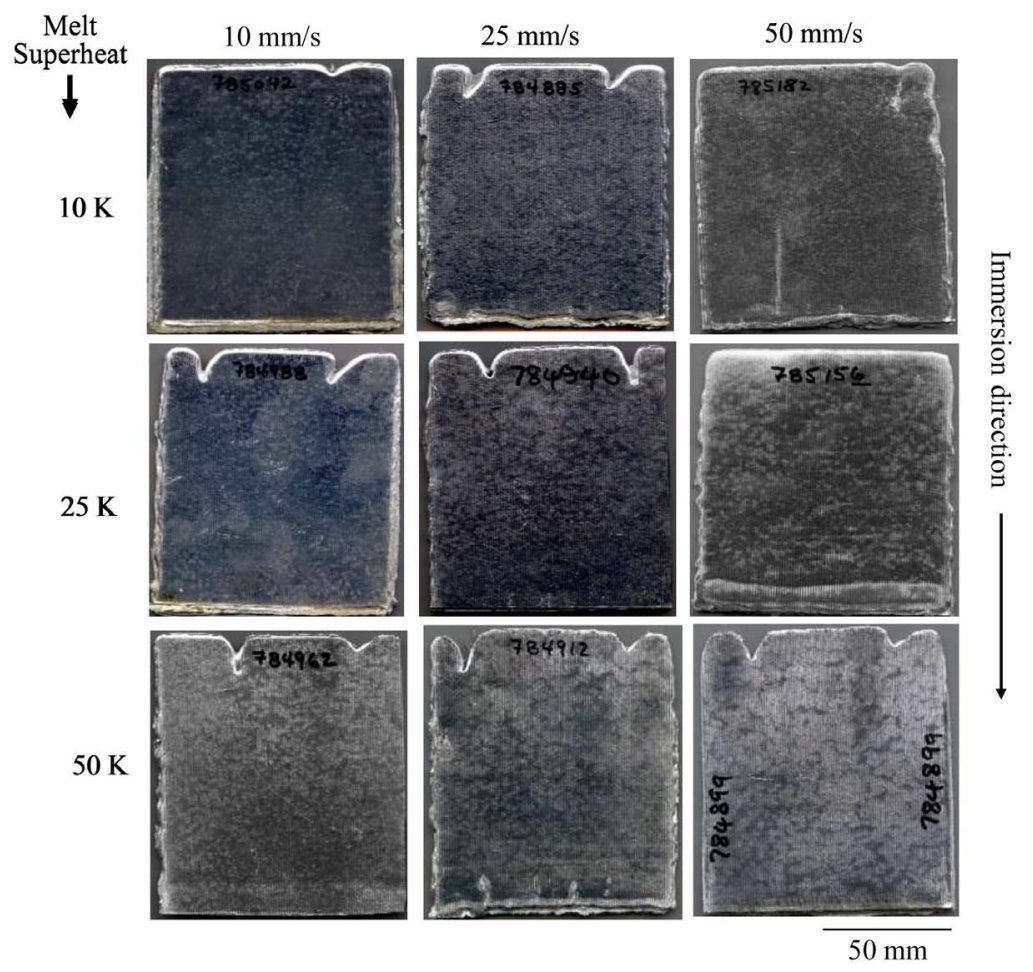

Figure 11. Effect of immersion (casting) speed and superheat on as-cast surface of ingot shells produced by immersion of a copper chill block with machined vertical grooves, $0.232 \mathrm{~mm}$ deep and $1 \mathrm{~mm}$ apart, surface topography into an AA 3003 melt.

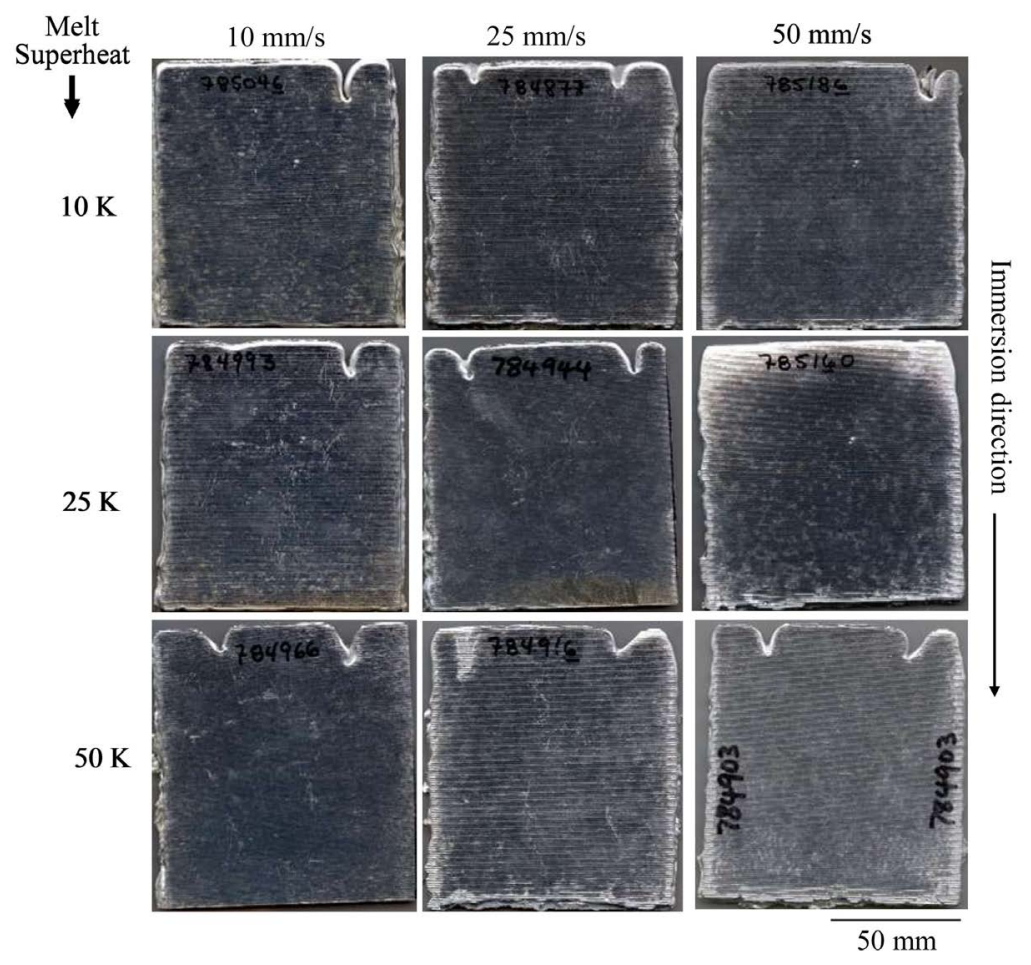

Figure 12. Effect of immersion (casting) speed and superheat on as-cast surface of ingot shells produced by immersion of a copper chill block with machined horizontal grooves (0.232 $\mathrm{mm}$ deep and $1 \mathrm{~mm}$ apart) surface topography into an AA 3003 melt. 
chill blocks with horizontal grooves that are perpendicular to the casting direction (Figure 8, Figure 10 and Figure 11). Most importantly, the prevalence of ripples and laps was significantly reduced and in some cases completely eliminated (Figure 11 and Figure 12). However, at $1 \mathrm{~mm} / \mathrm{s}$, the chill blocks with both vertical and horizontal grooves produced shells with ripples and laps. In the shells produced with the chills with vertical groove spacing between 5 and 15 $\mathrm{mm}$, the number of laps decreased and the spacing between the laps increased with increase in casting speed and melt superheat. However, the ingot shells produced with the copper mold chill block with vertical grooves with $1 \mathrm{~mm}$ spacing at casting speeds of $5 \mathrm{~mm} / \mathrm{s}$ or more were free from laps. Interestingly, at casting speeds of $5 \mathrm{~mm} / \mathrm{s}$ or more, the ingot shells produced on chills with horizontal grooves were free of laps. Unlike with the vertical grooves, copper mold chill blocks with horizontal grooves, $5 \mathrm{~mm}$ or more apart, produced shells that were free from laps (Figure 5). The pitch of the surface marks (i.e., distance between them) on the shells solidified on the chill blocks with horizontal grooves at $1 \mathrm{~mm} / \mathrm{s}$ was practically equivalent to the spacing between the grooves.

In general, the subsurface microstructure of the shells solidified on the copper chill with smooth surface topography was non-uniform and consisted of eutectic-enriched segregation layer with signs of solid shell remelting-induced liquation (Figures 13-15). The subsurface microstructures of the shells solidified on chills with grooved surface topography were comparatively more uniform than the subsurface microstructure of the shells produced with the smooth mold surface topography (Figure 14 and Figure 15). In general, however, there were

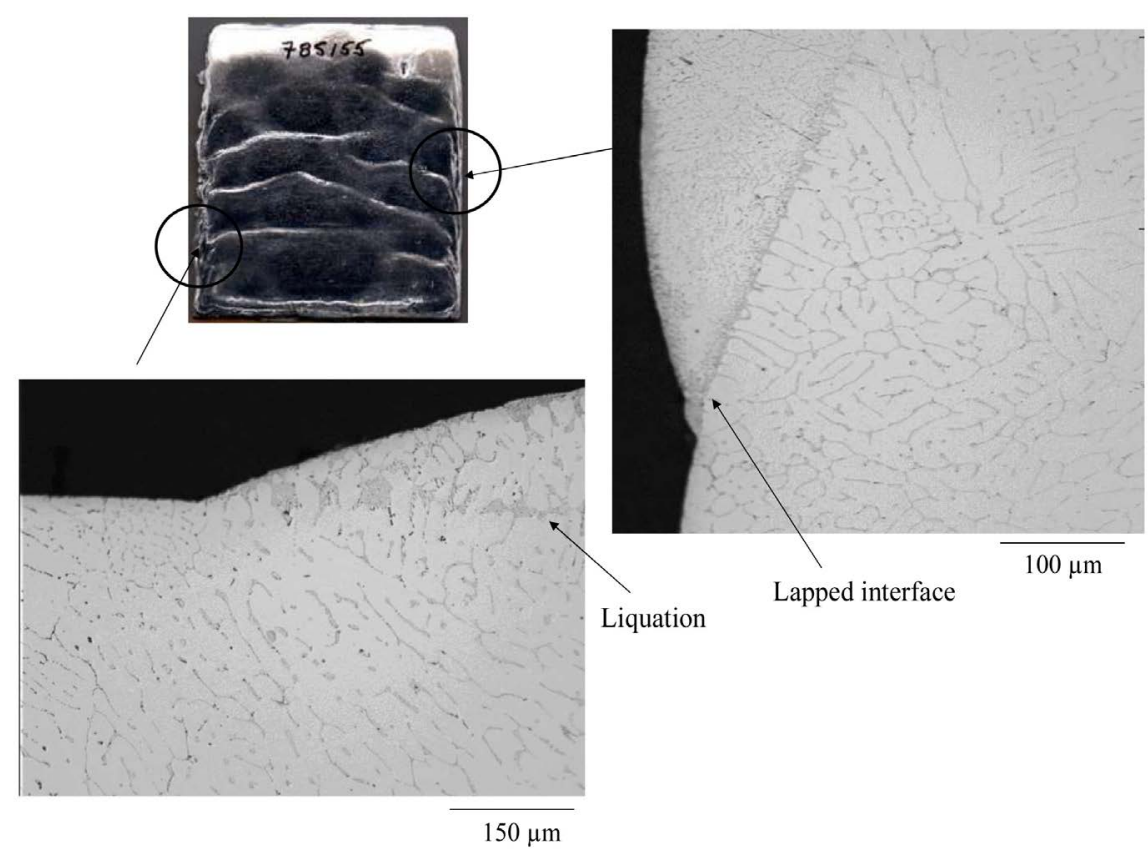

Figure 13. Photomicrographs showing the liquation (inverse segregation) associated with the surface laps on ingot shells of AA 3003 produced by immersion of a copper chill block with a machined smooth (non-grooved) surface topography into the melt at $50 \mathrm{~mm} / \mathrm{s}$ and $25 \mathrm{~K}$ superheat (Etched in $0.5 \% \mathrm{HF}$ for $12 \mathrm{~s}$ ). 


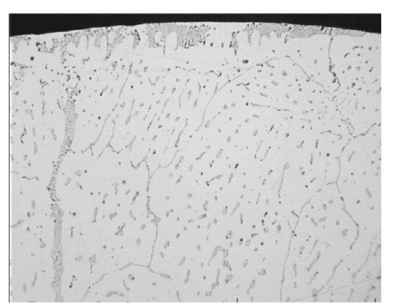

(a) Smooth - no grooves

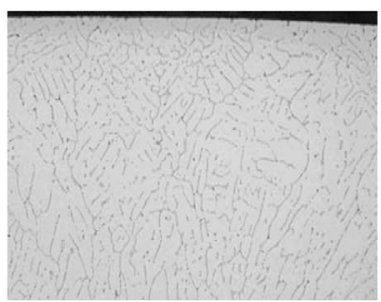

$150 \mu \mathrm{m}$

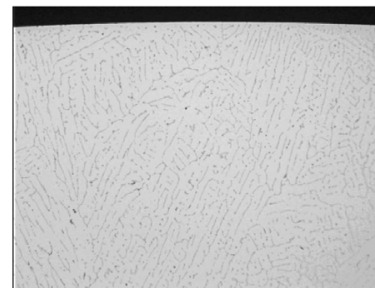

(c) $5 \mathrm{~mm}$ - vertical grooves

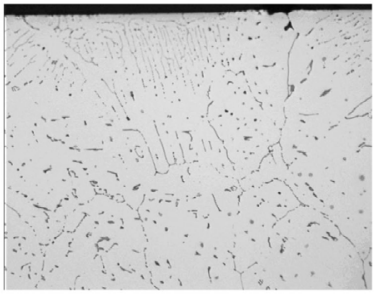

(d) $10 \mathrm{~mm}$ - vertical grooves

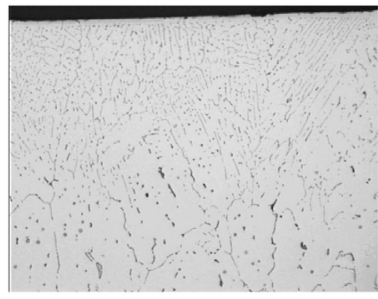

(e) $15 \mathrm{~mm}$ - vertical grooves

Figure 14. Photomicrographs showing the effect of the wavelength of $0.232 \mathrm{~mm}$ deep vertical grooves on a copper mold surface on the subsurface microstructure of AA 3003 shells produced by immersion of copper chill blocks at $50 \mathrm{~mm} / \mathrm{s}$ and $25 \mathrm{~K}$ superheat (Etched in $0.5 \% \mathrm{HF}$ for $12 \mathrm{~s}$ ).

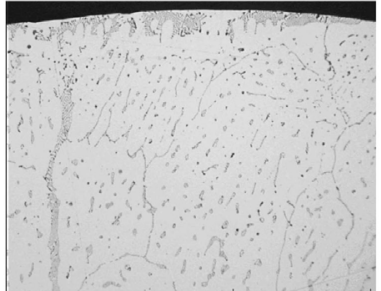

(a) Smooth (no grooves)

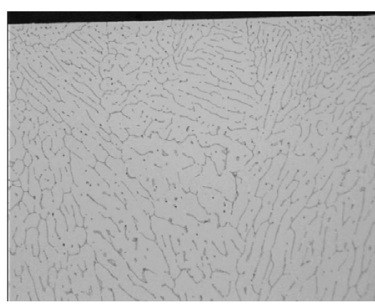

(b) $1 \mathrm{~mm}$ - horizontal grooves
$150 \mu \mathrm{m}$

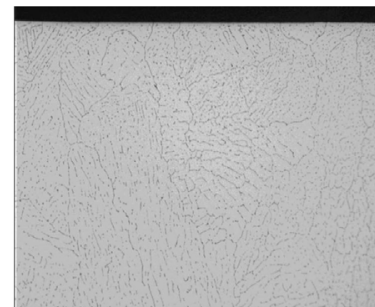

(c) $5 \mathrm{~mm}$-horizontal grooves

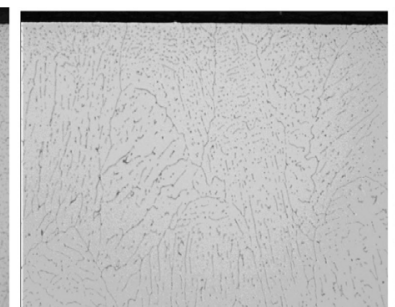

(d) $10 \mathrm{~mm}$ - horizontal grooves

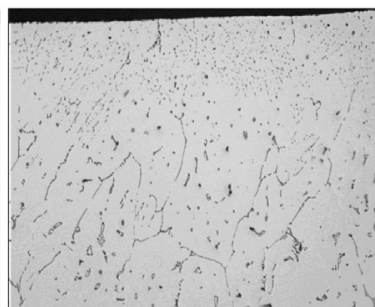

(e) $15 \mathrm{~mm}$ - horizontal grooves

Figure 15. Photomicrographs showing the effect of the wavelength of $0.232 \mathrm{~mm}$ deep horizontal grooves on a copper mold surface on the subsurface microstructure of AA 3003 shells produced by immersion of copper chill blocks at $50 \mathrm{~mm} / \mathrm{s}$ and $25 \mathrm{~K}$ superheat (Etched in $0.5 \% \mathrm{HF}$ for $12 \mathrm{~s}$ ).

signs of surface segregation in the subsurface microstructures of shells solidified on grooved mold chill blocks with a $15 \mathrm{~mm}$ wavelength. In contrast, the subsurface microstructures of the shells solidified on the chills with surface topography grooves with $1 \mathrm{~mm}$ spacing were uniform and free of segregation (Figure 14 and Figure 15). In fact, results of electron microprobe analysis of the subsurface microstructures presented in Figure 16 confirmed significant reduction in the segregation of manganese in the shells solidified on chills with $1 \mathrm{~mm}$ grooved 


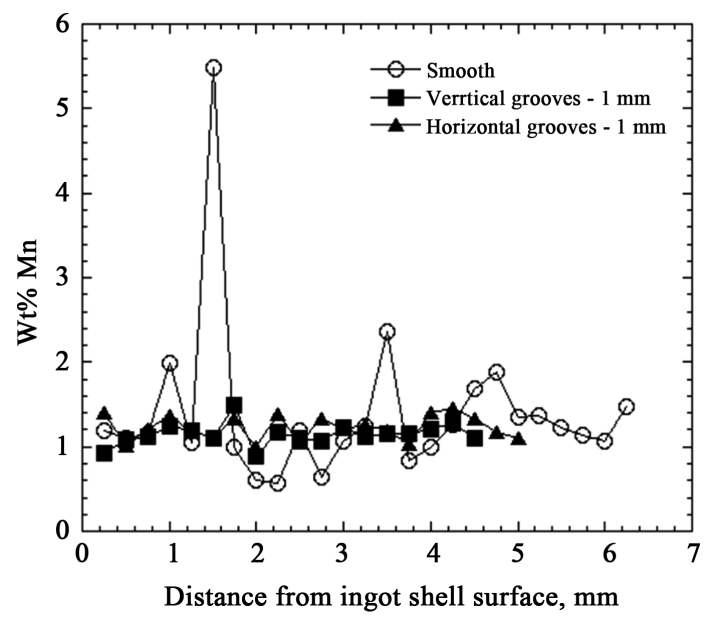

Figure 16. Results of electron microprobe analysis of the subsurface microstructures of as-cast aluminum alloy 3003 shells cast at $50 \mathrm{~mm} / \mathrm{s}$ and $25 \mathrm{~K}$ melt superheat showing the effect of mold surface topography on the segregation of Mn.

surface topography. The orientation of the unidirectional grooves to the casting direction (or molten metal surface) did not affect the subsurface microstructures of the cast shells. There was no discernible difference between the subsurface microstructures of shells solidified on vertical and horizontal grooved chills.

\section{Discussion}

It is apparent from the results that casting with molds with parallel contoured unidirectional grooved surface topography can have profound effects on the as-cast surface quality of an aluminum alloy cast product. The extent of the effects depends on the casting speed, melt superheat, and the wavelength and orientation of the grooves to the casting direction.

The characteristics and prevalence of surface marks observed on the chill as-cast surface of the ingot shells are similar to those of Types I, II, and possibly III meniscus marks reported by Wray [21] from decanting tests of molten lead solidified on a copper plate. It appears that the observed coarser and more widely spaced lap marks that formed at faster casting speed and higher melt superheat (Figure 3 and Figure 4) are Type II marks instead of Type III marks. According to Wray [21], Type III marks form at low casting speed and low degree of melt superheat. The ripples and lap marks observed in this study are also similar to those reported by Weirauch et al. [39] [40] from immersion tests in molten pure aluminum and aluminum alloys, Ackerman et al. [8], Jacobi and Schwerdtfeger [23], and Saucedo et al. [9]. The slightly downward bent corners of the surface marks and the fact that they are perpendicular to the casting direction are consistent with the ripple and lap marks that form on commercial-size ingots [1] [2] [3] and continuous cast products [4].

Ripple and lap marks are sometimes collectively referred to as meniscus marks [9] [18] because they form at the meniscus or as cold shuts [13] [14] [29]. As previously stated, for simplicity, the surface marks observed in this study will be 
collectively referred to as laps or lap marks. They form by a cyclic solidification process that begins just after the initial contact between the molten metal and the mold surface as a thin solid shell grows outward from the mold surface along the liquid metal/vapor surface (meniscus) [8] [9] [17] [18] [20] [26]. The liquid periodically overrides the solid shell and re-establishes fresh chill contact generating the lap marks. Lap marks are indicative of a meniscus instability. They are apparently due to periodic wetting (or non-wetting), solidification of the curved part (a convex surface) of the meniscus in contact with the mold, followed by one or more of the following [8] [9] [17] [18] [20] [23] [26]: 1) flow of molten metal over the partially solidified meniscus, 2) remelting of the solidified shell, or 3) inward bending of the solid shell caused by shrinkage during and after solidification allowing the melt to overflow. These events are apparently aided by thermal distortion of the solidifying shell [21] [47] [48], oxide film on the molten metal surface that increases its surface tension [8], and/or and dynamic effects of the surface waves of the liquid [22]. The remelting or inward bending of the solid shell allows the eutectic-enriched liquid to periodically overflow over the partially solidified meniscus and/or bend the solid tip, thus forming the surface depression characteristic of the defect [8] [9]. Formation of lap marks is exacerbated by a heat imbalance at the meniscus curvature by either too much heat being conducted away or insufficient heat supplied to the meniscus region. As a result, the frequency (i.e., number) of laps marks can be reduced by one or a combination of the following: 1) reduction of the residence time of the melt in the meniscus by increasing the casting rate, 2) reduction of the rate of heat extraction by increasing the thermal resistance of the mold and the gap between the mold and the solidifying shell in the meniscus region, and 3) delay of solidification by superheating the melt, preheating of the mold, insulation of the mold, use of low thermal conductivity mold materials, and increasing the casting speed.

\subsection{Effect of Mold Surface Topography}

In general, casting with the copper mold chill blocks with vertical and horizontal grooves produced ingot shells that had significantly fewer lap marks than the copper chill with the smooth surface topography (Figures 7-10). In fact, ingot shells produced at casting speed faster than $1 \mathrm{~mm} / \mathrm{s}$ with mold chill blocks with horizontal grooves that are $1 \mathrm{~mm}$ or more apart were completely free from lap marks (Figure 7). The observed alleviation of lap formation on the AA 3003 shells with grooved mold surface topography is consistent with that reported by Irman [29]. However, a mold surface topography consisting of $0.1 \mathrm{~mm}$ deep vertical grooves (parallel to the casting direction) that are $1 \mathrm{~mm}$ apart for narrow freezing range alloys such as AA 3003 suggested by Irman [29] was not the most effective. The observed amelioration of ripple and lap mark formation can be attributed to three possible reasons, namely the effects of the grooves on: 1) the rate of heat extraction in the meniscus region, 2) wetting of the mold chill surface by the molten metal, and 3) wave motion of the meniscus. As described 
above, alleviation of the formation of lap marks requires the moderation of the rate of heat extraction (and consequently rate of solidification) from the meniscus region. It therefore appears that the grooved copper mold chill blocks alleviated or eliminated lap formation on the as-cast surface of the ingot shells by moderating the rate of heat extraction in the meniscus vicinity. That is, the grooves reduce meniscus solidification. This is probably because mold surfaces with grooves reportedly reduce heat flux or heat transfer coefficient or increase thermal contact resistance at the mold-melt interface [32] [33]. This is due to the trapped air in the grooves. On a smooth surface thermal contact resistance between the melt and the chill surface is low because little air is trapped in the surface cavities. In fact, in this study, the local heat flux (calculated from the temperature measurements) for the mold chill blocks with $1 \mathrm{~mm}$ spaced grooves is less than that for the mold with a smooth surface topography (Figure 17). As shown in Figure 18, they also exhibited the lowest maximum interfacial heat

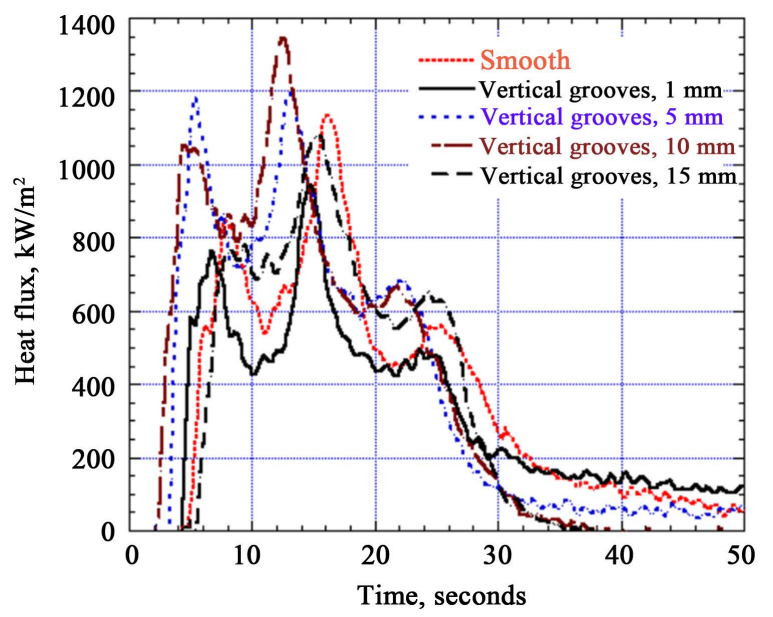

(a)

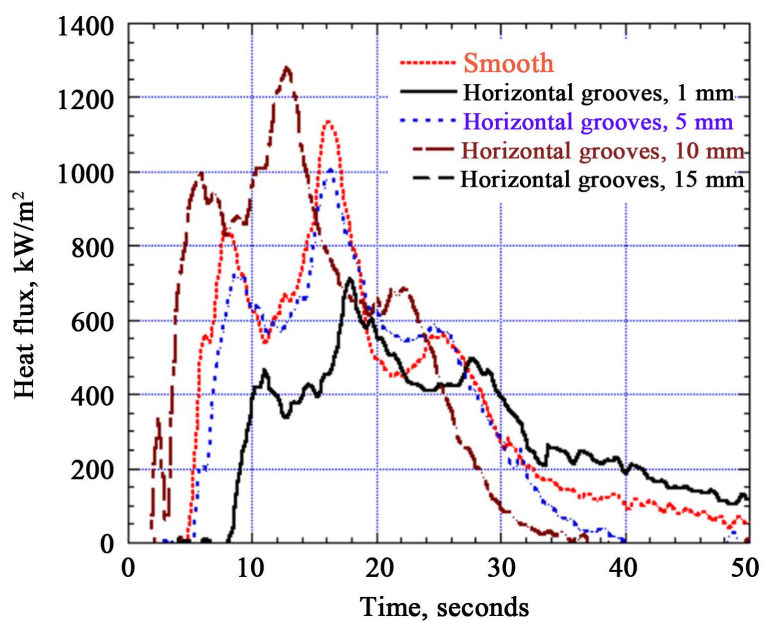

(b)

Figure 17. Effect of groove wavelength on calculated interfacial heat flux during solidification of AA 3003 on grooved copper chill blocks ( $5 \mathrm{~mm} / \mathrm{s}$ and $25 \mathrm{~K}$ melt superheat). (a) Molds with vertical grooves; (b) Molds with horizontal grooves. 


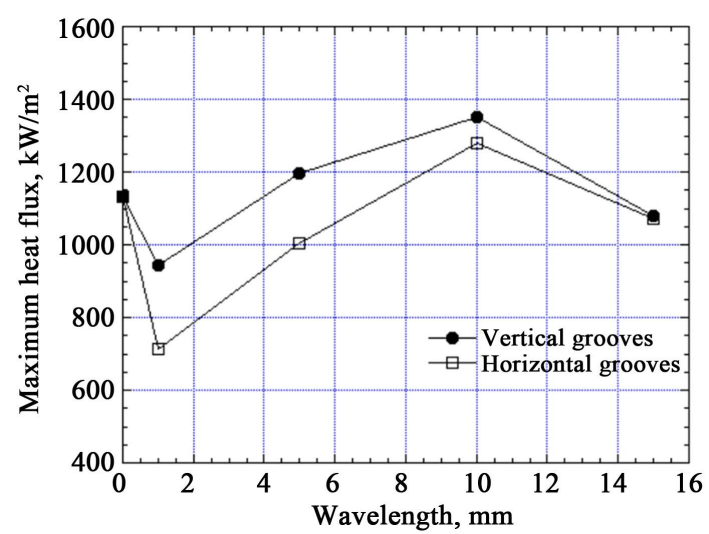

Figure 18. Effect of groove wavelength or spacing on maximum interfacial heat flux during solidification of AA 3003 on grooved copper chill blocks $(5 \mathrm{~mm} / \mathrm{s}$ and $25 \mathrm{~K}$ melt superheat).

flux during solidification of the shells. However, 5 - $15 \mathrm{~mm}$ spaced grooves on the mold chill surface resulted in higher interfacial heat flux than that obtained with a smooth mold surface topography. This is consistent with the reported effects of grooved mold surface topography on heat flux at metal-mold interface during solidification by some investigators. For example, Murakami et al. [34] reported $10 \%-30 \%$ increase in heat flux in the first 5 seconds of the solidification of hypoperitectic steel on a water-cooled chill with $1-5 \mathrm{~mm}$ spaced vertical grooves compared to that on a smooth copper mold. Bouchard et al. [27] [28] reported even higher increase in heat flux obtained in the early stages $(<0.5 \mathrm{~s})$ of solidification of a copper alloy on a water-cooled sand blasted copper chills and copper chills with $0.5-2 \mathrm{~mm}$ deep vertical grooves with $0.15-1 \mathrm{~mm}$ spacing. This suggests that the observed alleviation of surface lap marks with grooved mold surface topography is not entirely due to moderation of interfacial heat transfer.

It is also conceivable that the grooves on the chill surface disrupt the meniscus instability and the associated formation of the surface marks by enhancing the uniformity of degree of wetting of the mold chill surface by the molten metal. The replication of the main features of the grooved chill surface topographies (especially the horizontal grooves) indicates good wetting of the crests of the chill surface by the liquid metal (Figure 3 and Figure 4) and the non-wetting of the grooves. The non-filling and non-wetting of the troughs of the grooves are engendered by surface tension of the oxide-covered melt surface. Another possible reason for the alleviation of ripple and lap surface marks on the ingots with a grooved mold surface topography is that the grooves disrupt the gravity-induced waves on the surface of the molten metals which occur during the immersion casting [22] [23].

Horizontal grooves with $5 \mathrm{~mm}$ or more spacing are more effective than vertical grooves in precluding lap formation (Figure 11 and Figure 12). In fact, there is a strong correspondence between the surface condition of the mold chill block with horizontal grooves and that of its shells. This strongly suggests that better 
wetting conditions were present just before the AA 3003 alloy solidified against the horizontally grooved mold surface. It is particularly noteworthy that, at the slowest casting speed $(1 \mathrm{~mm} / \mathrm{s})$ investigated, none of the grooved copper chills could prevent the formation of laps on the as-cast surface of the shells. This implies that grooved mold surfaces will be more effective in alleviating the formation of as-cast surface defects such as lap marks (or cold shuts) in continuous casting than in ingot casting processes, with casting speed range of $50-230$ $\mathrm{mm} / \mathrm{s}$ and $0.5-1 \mathrm{~mm} / \mathrm{s}$, respectively [4].

\subsection{Effects of Casting Speed}

The observed effects of casting speed on finer and closely spaced ripple (Type I) and the coarser and wider spaced lap (Type II) marks depend on the type of mold surface topography. Formation of both types of surface marks on the ingot shells solidified on the mold with a smooth topography are much more sensitive to casting speed than the limited surface marks on the ingot shells solidified on the mold with grooved surface topography (Figure 7 and Figure 8). For example, it was found qualitatively that, with the exception of the ingot shells solidified on chill blocks with horizontal grooves, the spacing between the Type I surface marks (i.e., ripples) appeared to be independent of casting speed (Figure 3).

The effects of casting speed on the formation of surface marks, especially the finer and closely spaced ripple (Type I) marks, have been studied quantitatively by several investigators [8] [15] [16] [17] [20] [21] [22] [23] [24] [26] [39] [40]. The studies have involved careful quantitative profile measurement of ripple spacing and groove depth as functions of casting speed and melt superheat. Most of these investigators reported that increase in casting speed decreases the depth of and spacing between surface marks [8] [15] [16] [17] [20] [21] [22] [23] [24] [26], apparently improving the surface quality of the ingots. This is attributed to its effect on the formation of the solid skin at the edge of the meniscus. According to Jacobi and Schwerstfeger [23], at faster casting speed (which is equivalent to the rise of the meniscus) the tip of the skin may be located in the lower part or below the curved edge of the meniscus. However, decreasing the casting speed could cause the tip to move upwards and into the curvature, thus enhancing melt overflow and exacerbating ripple formation. That is, the slower casting speed allows the shell to solidify along the meniscus well away from the mold wall. Interestingly, consistent with the results of this study, Stemple et al.'s [22] found the finer Type I marks, which they referred to as secondary ripples, to be independent of casting speed. It is noteworthy that these fine and closely spaced ripple (Type marks) run undisturbed through the coarser and widely spaced lap (Type II) marks (Figure 4). This strongly suggests that the ripple marks formed prior to the formation of the lap marks. The latter, as explained below, are said to be engendered by thermal stresses in the solidifying shell.

However, in contrast to its effect on the Type I marks (ripples), increase in casting speed appears to increase the spacing and depth of the more widely spaced and coarser Type II (lap) marks (Figures 3-6). This result confirms 
Wray's [21] and Stemple et al.'s [22] observations. Wray [21] reported that the spacing between the more widely spaced lap marks, which he referred to as Type II marks, increased with increase in casting speed. Wray [21] attributed the observed contrasting effects of casting speed on the formation of ripples and lap marks to the differences in the mechanisms for the formation of both types of surface marks. According to Wray [18], the widely spaced Type II surface marks are caused by distortion of the ingot shell engendered by the thermal stresses developing in the shell during solidification. Type II marks apparently do not form at the meniscus but at some distance below the meniscus line due to temperature perturbations that cause uneven thickening of the shell. Thus, they are associated with the non-uniform thickening or growth of the shell. Stemple et al. [22] also found that the spacing between the more widely spaced clearly delineated surface marks, which they referred to as primary surface marks, on bottom-poured $\mathrm{Sn}-\mathrm{Pb}$ ingots increased linearly with increase in casting speed. They contend that surface marks (which they refer to as primary ripples) are caused by surface waves, gravity induced meniscus motion, during filling of the mold. On the basis of wave theory, the spacing between the surface marks can be shown to be directly proportional to the casting speed [23].

Qualitatively, it is well known that surface ripple marks on castings can be eliminated or reduced by eliminating the meniscus or by reducing heat extraction in the vicinity of the meniscus during the early stages of solidification [13] [14] [49]. This can be accomplished by increasing casting speed, changing lubrication practice, using higher frequencies of mold oscillation (in continuous casting of steels), use of low thermal conductivity mold materials, high melt superheating, etc. Increasing the casting speed reduces the residence time in the meniscus in accordance with Equations (1) and (2):

$$
t_{r}=\frac{b}{V_{c}}
$$

where $t_{r}=$ residence time in the meniscus, $V_{c}=$ the casting speed, and $b=$ meniscus height which represents the vertical distance during which the mold-casting heat exchange occurs in the meniscus region; it depends on the surface tension and density of the molten alloy in accordance with the equation:

$$
b=\left(\frac{2 \gamma}{g \rho}\right)^{1 / 2}
$$

where $b=$ meniscus height, $\gamma=$ surface tension of the molten metal, $g=$ acceleration due to gravity, and $\rho=$ density of the molten metal.

It is also noteworthy that rapid changes in temperature gradient may exacerbate thermal distortion of the shell tip which may alter the rate of solidification near the meniscus and ultimately the shape of the meniscus-based surface marks. It is conceivable that there are two (or more) different mechanisms for the formation of different types of surface marks and/or at different casting speeds. At slow casting speeds, formation of surface marks is probably caused by 
the overflow mechanism resulting in irregular pitch (spacing) and depth. In this case, the casting rate is sufficiently slow that the shell has time to solidify along the meniscus away from the mold or chill block wall. That is inward bending of the solid shell which would allow the melt to overflow the solidified meniscus near the mold wall and form a ripple [9] [17] [20]. At faster casting rates however, surface marks are probably formed by the folding mechanism [26].

\subsection{Effect of Melt Superheat}

Like the casting speed, the effects of melt superheat on ripple (Type I) and lap (Type II) marks also depend on the type of mold surface topography. The surface marks on the shells solidified on the mold with a smooth topography are much more sensitive to melt superheat than the limited surface marks on the shells solidified on the mold with grooved surface topography (Figure 9 and Figure 10). Also, the melt superheat has contrasting effects on the narrowly spaced Type I marks (ripple) and the widely spaced Type II (lap) marks. However, in general, the effects of melt superheat are not as pronounced as that of casting speed. For example, increase in melt superheat appeared to decrease the distance between the Type I marks, the ripples. In fact, qualitatively, at a casting speed of $50 \mathrm{~mm} / \mathrm{s}$ and $50 \mathrm{~K}$ melt superheat, it appears that the ripples are eliminated, only the coarser and wider spaced lap marks are left (Figure 9 and Figure 10). The observed effects of melt superheat on Type I marks are consistent with the reported effects of melt superheat on the formation of surface marks on the as-cast surfaces of aluminum alloy ingots by several investigators [8] [9] [15] [21] [22] [23] [24] [25]. For, example, qualitatively, Thornton [24] and Saucedo et al. [9] reported that the "degree or severity of rippling" was reduced by increase in melt superheat. Several investigators [8] [15] [21] [23] [25] quantitatively found that increase in melt superheat decreased the spacing and depth of Type I (ripples). The effect of melt superheat on the finer Type I surface marks (ripples) can be attributed to its effect on the rate of solidification or heat extraction at the meniscus region. Increase in melt superheat decreases the meniscus solidification. At sufficiently high melt superheat and casting speed, which in this study are $50 \mathrm{~K}$ and $50 \mathrm{~mm} / \mathrm{s}$, respectively, the fine ripples are completely eliminated.

The effects of melt superheat on the widely spaced and coarser (Type II) lap surface marks depend on the casting speed (Figure 6). At the fastest casting speed, $50 \mathrm{~mm} / \mathrm{s}$, increase in melt superheat increased the measured average distance between the coarse lap (Type II) marks (Figure 6). This suggest that, like the Type I marks, at the fastest casting speed, increase in melt superheat decreases the frequency and possibly severity of lap marks on ingot surfaces produced with a mold surface topography. This can be attributed to the decrease in meniscus solidification and the overall decrease in solidification rate of the ingot at higher melt superheats. According to Wray [21], the widely spaced and coarser Type II surface marks do not form at the meniscus but at some distance below 
the meniscus line because of the distortion of the shell at the early stages of solidification. The distortion of the shell is engendered by the thermally induced mechanical stresses developing in the solidifying and thickening shell. The slower rate of solidification is also expected to result in less distortion of the ingot shells.

However, at slower casting speeds (10 and $25 \mathrm{~mm} / \mathrm{s}$ ), increase in melt superheat slightly decreased the distance between the widely spaced lap (Type II) marks (Figure 6). These results are consistent with the observations by Stemple et al. [22] and Jacobi and Schwerdtfeger [23]. Stemple et al. [22] did not find any significant effect of melt superheat on the spacing between what they referred to as primary ripple marks. Whereas, Jacobi and Schwerdtfeger [23] found that increase in melt superheat decreased the space between Type II surface marks which they referred to as transverse depressions.

It is noteworthy, however, that solidification on grooved mold surface topography either eliminates or significantly decreases the sensitivity of both ripple and lap mark formation to melt superheat. As apparent in Figure 11 and Figure 12 , ripples and lap marks are completely eliminated on cast shells solidified on copper mold with $1 \mathrm{~mm}$ spaced vertical or horizontal molds at casting speed of $10 \mathrm{~mm} / \mathrm{s}$ and above, and melt superheat of $10 \mathrm{~K}$ and above. The practical implications of these results are significant. They suggest that formation of ripples and lap marks can be avoided in direct chill cast ingots and continuous cast slabs and bars by using molds with $1 \mathrm{~mm}$ spaced grooves. There is also an indication that these surface marks can be avoided with the grooved mold surface topography in stationary bottom poured castings. Most importantly, the non-uniform subsurface microstructural features of the cast ingots such as liquation associated with the surface laps and ripples can also be alleviated by casting with molds with grooved surface topography.

\section{Conclusions}

1) In general, casting of aluminum alloy 3003 with copper molds with vertical or horizontal grooves produced ingots with significantly fewer ripple (Type I) and lap (Type II) surface marks than casting with copper molds with a smooth surface topography. This was particularly the case at casting speeds greater than $5 \mathrm{~mm} / \mathrm{s}$.

2) Increase in casting speed and melt superheat appeared to decrease the propensity for formation of ripple and lap surface marks on ingots produced with copper molds with smooth surface topography.

3) The critical wavelength (spacing) for grooves on a grooved mold surface topography for significant alleviation of lap surface mark formation during immersion (or continuous) casting of aluminum alloy 3003 on a copper chill is 1 $\mathrm{mm}$. This is independent of the orientation of the grooves to the casting direction.

4) At $5 \mathrm{~mm}$ or more spacing, grooves perpendicular to the casting direction (horizontal) appear to be more effective than those that are parallel to the casting 
direction (vertical) in alleviating the formation of ripple and lap surface marks on cast ingots of aluminum alloy 3003 .

5) Casting with a mold surface topography with $1 \mathrm{~mm}$ spaced grooves eliminated the formation of subsurface liquation (inverse segregation) and engendered a more uniform subsurface cast microstructure on ingots of aluminum alloy 3003 .

\section{Conflicts of Interest}

The author declares no conflicts of interest regarding the publication of this paper.

\section{References}

[1] Emley, E. (1976) Continuous Casting of Aluminum. International Metals Review, 6, 75-115. https://doi.org/10.1179/imtr.1976.21.1.75

[2] Buxmann, K. (1978) Surface Faults in Aluminum Continuous Casting. Aluminum, 54, 685-690.

[3] Nofal, A. (1992) Surface Defect Formation in the DC-Cast Aluminum Products. Proceedings of Advances in Continuous Casting Research \& Technology, Cairo, 13-15 April 1992, 205-218.

[4] Anyalebechi, P.N. (2004) Technical Issues Impeding the Proliferation of Continuous Casting Processes in the Aluminum Industry. In: Schlesinger, M.E., Ed., EPD Congress 2004, The Minerals, Metals, and Materials Society, Pittsburgh, 191-215.

[5] Gjonnes, L. (1996) Development of Surface Topography during Cold Rolling of Twin-Roll Cast Aluminum. Wear, 192, 216-227. https://doi.org/10.1016/0043-1648(95)06809-0

[6] McCubbin, J.G. (1975) Inverse Solidification-A Theory of the Formation of the Surface Segregation on D.C. Cast Round Ingot. Light Metals, 2, 137-159.

[7] Vosskuhler, H.Z. (1965) Inverse Segregation in Ingots of Nonferrous Metals. $\mathrm{Me}$ tallkde, 56, 719-729.

[8] Ackermann, P., Heinemann, W. and Kurz, W. (1984) Surface Quality and Meniscus Solidification of Pure Chill Cast Metals. Archiv für das Eisenhüttenwesen, 55, 1-8. https://doi.org/10.1002/srin.198405298

[9] Saucedo, I., Beech, J. and Davies, G.J. (1982) Influence of Meniscus Freezing on Surface Defect Formation in Cast Products. In: Solidification in the Foundry and Cast House, The Metals Society, London, 461-468.

[10] Collins, D.W.L. (1967) New Explanation of the Surface Structure of D.C. Ingots. Metallurgia, 137, 137-144.

[11] Bergmann, W.J. (1970) Solidification in Continuous Casting of Aluminum. Metallurgical Transactions, 1, 3361-3364.

[12] Nussbaum, A.I. (1995) Two State of the Art Ingot Scalping Installations. Light Metal Age, 10, 10-12.

[13] Weckman, D.C. and Niessen, P. (1984) The Mechanism of Cold Shut Formation on D.C. Continuously Cast Non-Ferrous Alloy Products. Zeitschrift für Metallkunde, 75, 414-422.

[14] Weckman, D.C. (1987) Horizontal Direct-Chill Continuous Casting of Non-Ferrous Alloy Rods. Zeitschrift für Metallkunde, 78, 880-886. 
[15] Quaresma, J.M. and Garcia, A. (1983) Analysis of the Factors Influencing the Formation of Surface Defects on Ingots. Proceedings of 38 th Annual Congress ABM, Vol. 4, 303-324.

[16] Quaresma, J.M.V., Cheung, N. and Garcia, A. (2007) The Effect of Solidification Thermal Variables on Surface Quality of Al-Cu Ingots. Journal of Alloys and Compounds, 428, 130-138. https://doi.org/10.1016/j.jallcom.2006.03.054

[17] Malinovskii, R.R. (1987) Causes of Wrinkles Formation in Continuous Casting of Aluminum Alloys. Tsvetnye Metally/Non-Ferrous Metals, 90, 74-76.

[18] Saucedo, I., Beech, J. and Davies, G.J. (1979) The Development of Surfaces in Steel Ingots and Strands. In: Proceedings of 6 th Vacuum Metallurgy Conference on Special Melting, American Vacuum Society, New York, 885-905.

[19] Benum, S., Hakonsen, A., Hafsa, J.E. and Sivertsen, J. (1999) Mechanisms of Surface Formation during Direct Chill (DC) Casting of Extrusion Ingots. In: Eckert, C.E., Ed., Light Metals 1999, The Minerals, Metals \& Materials Society, Pittsburgh, 737-742.

[20] Tomono, H., Kurz, W. and Heinemann, W. (1981) The Liquid Steel Meniscus in Molds and Its Relevance to the Surface Quality of Castings. Metallurgical Transactions B, 12, 409-411. https://doi.org/10.1007/BF02654475

[21] Wray, P.L. (1981) Geometric Features of Chill-Cast Surfaces. Metallurgical Transactions B, 12, 167-176. https://doi.org/10.1007/BF02674770

[22] Stemple, D.K., Zulueta, E.N. and Flemings, M.C. (1982) Effect of Wave Motion on Chill Cast Surfaces. Metallurgical Transactions B, 13, 503-509. https://doi.org/10.1007/BF02667767

[23] Jacobi, H. and Schwerdtfeger, K. (2013) Ripple Marks on Cast Steel Surfaces. ISIJ International, 53, 1180-1186. https://doi.org/10.2355/isijinternational.53.1180

[24] Thornton, D.R. (1956) An Investigation on the Function of Ingot Mould Dressings. The Journal of the Iron and Steel Institute, 300-315.

[25] Suzuiki, M. and Yamaoka, Y. (2003) Influence of Carbon Content on Solidifying Shell Growth of Carbon Steels at the Initial Stage of Solidification. Materials Transactions, 44, 836-844.

[26] Tomono, H., Ackermann, P., Kurz, W. and Heinemann, W. (1980) Elements of Surface Marks in the Continuous Casting of Steel. In: Conference Proceeding, Solidification Technology in the Foundry and Cast House, Warrick University, Coventry, 524-531.

[27] Bouchard, D., et al. (2001) Effects of Substrate Surface Conditions on Heat Transfer and Shell Morphology in Solidification of a Copper Alloy. Metallurgical and Materials Transactions B, 32, 111-118. https://doi.org/10.1007/s11663-001-0013-y

[28] Bouchard, D., et al. (2002) Control of Heat Transfer and Growth Uniformity of Solidifying Copper Shells through Substrate Temperature. Metallurgical and Materials Transactions B, 33, 403-411. https://doi.org/10.1007/s11663-002-0052-Z

[29] Irman, R. (1952) Continuous Casting of Aluminum in a Grooved Mold. Giesserei, 6-8, 393-394.

[30] Buxmann, K., Bolliger, L.M. and Gyongyos, I. (1981) Mould with Roughened Surface for Casting Metals. US Patent No. 4,250,950.

[31] Mizikar, E.A., Wojcik, W.M. and Li, K. (1967) U.S. Letters Patent No. 3,345,738.

[32] Sugitani, Y., et al. (1985) Effect of the Mould Surface Conditions on Uneven Solidification and Heat Removal Rate through the Mould. Transactions of the Iron and Steel Institute of Japan, 25, B-91. 
[33] Nakai, K., et al. (1985) Improvement of Surface Quality of Continuously Cast Slab by Reducing Heat Flux Density in Mould. Proceedings of Shanghai Symposium on Continuous Casting, Shanghai, December 1985, 71.1-71.8.

[34] Murakami, H., et al. (1992) Control of Uneven Solidified Shell Formation of Hypoperitectic Carbon Steels in Continuous Casting Mould. Journal-The Iron and Steel Institute of Japan, 8, 105-112.

[35] Gaspar, T. (1987) U.S. Letter Patent No. 4,705,095.

[36] Bartlett, E., Maringer, R. and Rayment, J. (1989) U.S. Letter Patent No. 4,865,117.

[37] Nakada, M., et al. (1990) Canadian Patent Application No. 2,000,618.

[38] Tanaka, S., et al. (1988) European Patent Application No. 0309247A2.

[39] Weirauch, D.A. and Giron, A. (1999) The Early Stages of Aluminum Solidification in the Presence of a Moving Meniscus. In: Zabaras, N., et al., Eds., Proceedings of a Conference on the Integration of Material, Process, and Product Design, Balkema, Rotterdam, 183-191.

[40] Weirauch, D.A., et al. (2000) Laboratory Study of Cast Surface Structure Evolution I: Mold-Contact Stage. In: Peterson, R.D., Ed., Light Metals 2000, The Minerals, Metals, and Materials Society, Pittsburgh, 649-656.

[41] Morishita, M., Nakayama, K., Tokuda, K. and Yoshikawa, K. (2000) Laboratory Study of Cast Surface Structure Evolution II-Macro Air Gap Stage. In: Peterson, R.D., Ed., Light Metals 2000, The Minerals, Metals, and Materials Society, Pittsburgh, 657-662.

[42] Hunter, N.S., et al. (1999) The Influence of Mould Metallurgy on Surface Defects in Peritectic Carbon and Austenitic Stainless Steels. La Revue Metallurgie Cahiers D' Informations Techniques, 96, 473-482. https://doi.org/10.1051/metal/199996040473

[43] Anyalebechi, P.N. (2007) Undulatory Solid Shell Growth of Aluminum Alloy 3003 as a Function of the Wavelength of Grooved Mold Surface Topography. In: Anyalebechi, P.N., Ed., Materials Processing Fundamentals, The Minerals, Metals, and Materials Society, Pittsburgh, 31-47.

[44] Anyalebechi, P.N. (2007) Ungrooved Mold Surface Topography Effects on Subsurface Microstructure. In: Anyalebechi, P.N., Ed., Materials Processing Fundamentals, The Minerals, Metals, and Materials Society, Pittsburgh, 49-62.

[45] Anyalebechi, P.N. (2008) Effect of Cross-Hatched Mold Surface Topography on Shell Morphology in the Solidification of an Aluminum Alloy. In: EPD Congress 2008, The Minerals, Metals, and Materials Society, Pittsburgh, 183-200.

[46] Anyalebechi, P.N. (2012) Effects of Mold Material and Casting Speed on Shell Morphology and Attendant Surface Microstructure of Aluminum Alloy 3003. International Foundry Research, 64, 20-32.

[47] Dong, S., Niiyama, E. and Anzai, K. (1994) Direct Observation of Deformation of Shell Solidified at Melt-Chill Contact. Materials Trans, 35, 196-198. https://doi.org/10.2320/matertrans1989.35.196

[48] Dong, S., et al. (1993) Free Deformation of the Initial Solid Layer of Some Non-Ferrous Alloys. Cast Metals, 6, 115-120. https://doi.org/10.1080/09534962.1993.11819135

[49] Saucedo, I., Beech, J. and Davies, G.J. (1982) Heat Transfer and Solidification Kinetics in Meniscus Zone during Casting. Metals Technology, 9, 282-291. https://doi.org/10.1179/030716982803285693 